\title{
Further Discussion on Hypothecateability of Domain Name Rights
}

\author{
Boyu Zhu \\ Law School \\ Shandong University of Technology \\ Zibo 255049, China \\ Tel: 86-533-278-2279 E-mail:zhuboyu123@126.com
}

\begin{abstract}
Domain name rights should be treated as a kind of unattached Intellectual property rights. Intellectual property rights differ from other subject matters of pledge in nature, but its nature is extremely similar to the subject matters of hypothec. It's well in the trend of statutory principle of modern property law to treat Intellectual property rights as subject matters of hypothec. Domain name rights may be hypothecated and realized in two ways. First, it can be classified as Intellectual property rights meeting the essential characteristics of hypothec property rights. Second, it may be subjected to an enterprise's collective mortgage, fulfilling the purpose of mortgage by putting the domain name rights into the enterprise's aggregately mortgaged property. In a domain name rights hypothecation regime, a public notification system should be expressly legislated and a valuation mechanism established and well developed.
\end{abstract}

Keywords: Domain name rights, Intellectual property rights, Hypothec, Pledge

The domain name (Domain Name) is also called the website, the digitized address of the computer connected to Internet, represents the applicant's identity which linked to Internet (Shou Bu,2003:p205). Appearance of the domain name has brought challenges for traditional civil law and how to reply legally has become the important subject that the modern civil law faces. The case whether the rights of the domain name could be mortgaged have already presented in U.S.A And the network technology of our country is developed and in more and more prosperous era, enough reasons are being believed that the similar dispute will present too in our country in the near future. So the study on this problem has important realistic meanings.

\section{The legal nature of the domain name}

The domestic scholar roughly has the following views to the nature of the rights of the domain name: (1) Lay aside temporarily. Mainly thinking the nature of the domain name rights can not confirm and need further observation yet to draw a conclusion. (2) The parlance of civil interests. The very close view to laying aside saying on methodology temporarily is the civil interests saying. Think though the domain name has not been protected as a kind of Intellectual property rights by WIPO yet, but might not deny it as a kind of civil rights and interests at least, otherwise the domain name will possibly be in no protected position awkwardly and passively. (3) The Intellectual property rights saying. A lot of scholars think the rights of the domain name belongs to the category of the Intellectual property rights, but the difference among them is very big.(Dong Hao,March 11,2004). I agree to the Intellectual property rights saying and think the domain name rights is a kind of independent Intellectual property rights.

\subsection{The rights of domain name should have the position of rights}

First of all, we should define the relation between the domain name and domain name rights. Like the works and copyrights, trade mark and trade mark privileges, the patent and patent rights in the law of Intellectual property rights, the domain name is different from the rights of the domain name and the domain name is an object of the rights of the domain name. Clarifying the relation between the two would not obscure the nature of the domain name and domain name rights. As regards domain name in the meaning of the object of rights, the domain name is a kind of technological symbol at first. The purpose to design domain name is used for getting in touch in computer networking and online communication, domain name just like telephone number, their function is just make one different with another in Internet. So the initial domain name only has a meaning on technology. However, with the development of the network technology and progress of social economy, the domain name has the value of commerce gradually and has played the 
function of "Online trade mark" for the trade company. The trade company often regards the trade mark or the trading company as the sign of domain name and makes use of business reputation loaded on the domain name to expand the propaganda of one's own products in order to bring consumer's attention. So, having a domain name that the public knew and related to the goods is the sign of trade company with good prestige and cognitive of market .Therefore, the domain name begins to have other functions --Function of the identification. Just this function makes the domain name begin to have the nature of "no body thing" Hong Xunxin, the scholar of Taiwan civil law said, "Besides human body, anything could be controlled by human and is exclusive and independence to make mankind meet society living needs, no matter it is body thing or no body thing, it is all a thing in law"(Wang Zejian,2001:p207).I think Professor Hong's view accords with the development trend of the law of modern real rights and it is worth agreeing. So considering the commercial value of domain name, domain name as "body things" in civil law has no question. But do the rights of the domain name have rights nature? Talk openly in accordance with the modern law circles, the nature of rights as the jurist of German Meiker recommend "legal power" is essential subject of rights enjoy specific interests and strength in law of(Long Weiqiu,2003:p120). So the key to distinguish rights and interests is whether these interests are given by the position of law. Law stipulate certain interests by form of conferment as the rights, on the contrary, it can only exist as certain interests but can't become rights. So if you want to know whether it is interests or rights needs to see the regulation of the law. I think the domain name should exist as a right. First of all, the commercial value of domain name loaded needs to protect indeed. If the law doesn't protect, it won't encourage enterprising spirit of oblige and it does not accord with the legislative purpose of the Intellectual property rights .Secondly, according to current legislation both at home and abroad, the protection of domain name mainly depends on Trademark Law and law against competition by inappropriate means to ensure. Domain name and trade mark have similarity, but the difference of the two is very obvious too. In many situations only according to Trademark Law or the law against competition by inappropriate means, the domain name owner's rights is difficult to receive prompt protection, so it is really necessary to give the domain name the position of rights to avoid the deficient protection to the rights of the domain name. After confirming the rights status of domain name rights, it still needs to investigate the position the domain name right in the system of civil rights, because not every civil rights was suitable for the mortgage token.

\subsection{The domain name should belong to the category of the Intellectual property rights}

The absolute rights which have the nature of property still divides into real rights and Intellectual property rights, so distinguishing the rights of the domain name is real rights or Intellectual property rights reflected the essential attribute of the domain name rights. The one that is worth probing into further is, whether the domain name forms the Intellectual property rights? According to the traditional civil law theory, the Intellectual property rights is the achievement rights of the intelligence and it condenses the creator's work in the Intellectual property rights, but the domain name is only one bunches of expression symbols from the technology. So speaking from the surface, it's hard to say the right of the domain name is the achievement rights of the intelligence. But a noteworthy one is in the design of the domain name work including certain intelligence. Domain name is that the trade company or user uses trade mark or trading company as mark, through a regular period of use, the domain name can play a role in citing prestige of trade company, become "online trade marks" of the trade company and the sign that consumers know the trade company on the net. So the domain name has function of the identification, has already become the sign that consumers distinguish this trade company and another trade company. And according to the stipulations of relevant domestic and international Intellectual property rights theories and international treaties, the concept of the Intellectual property rights has already been no longer confined to the category of the achievement rights of intelligence. The range of the Intellectual property rights has already been expanded to some extent. The rights of the commercial mark have already become one kind of the Intellectual property rights too. "The Intellectual property rights refer to the domination creative intelligence achievement that the civil subject is enjoyed, commercial sign and the rights that repel others to interfere."(Zhang Yumin,2001:p.105) The Intellectual property rights refers to the mark, prestige that people based on one's creating achievement and operational and managing activities to enjoy the rights in accordance with the law.(Wu Handong,2000:p1) International convention concerned Intellectual property rights have expanded and mark rights commercial such as "Establishing World Intellectual Property Organization's convention"in 1967 and "Intellectual property rights agreement " passed with General Agreement on Tariffs and Trade in 1993 has magnified the range of the Intellectual property rights. The rights of the commercial mark has already become one kind of Intellectual property rights which most scholar's approved. So domain name rights as a kind of intellectual property rights exists no problem

\section{The legal principle analysis of the Intellectual property rights can be the mortgage token}

The mortgage target called hypothec objects or the mortgage too, mean the mortgagor used for establishing the property of the hypothec (Guo Mingrui,1999:p114).Every country has legislated to limit mortgage token, some adopt "the active enumerating type ", some adopt "the passivism limiting type ", some adopt the two. "The People's Republic of China Assurance Law" limits mortgage token from positive respect and passive respect. But we should notice this development trend in the range of what has been probed into the mortgage token: The mortgage token is expanding constantly with the need of the development of social economy, we can't confine to the range of mortgage token that the 
traditional civil law stipulated. Just as Hu Zaiquan said: "The hypothec is subject matters in accordance with the real estate and rights of having real estate, the movable property must give play to it and assure function, but the his kind of system can't meet the need of the society yet because of gradual development of economy ." (Xie Zaiquan,1999:p546).A lot of legislation or theory have already affirmed movable property and some rights can regard as mortgage token too in many countries and regions, for example: " Trade Law of Movable Property Guarantee and "The Civil Code of Taiwan" in U.S.A. and Taiwan have already affirmed movable property and rights belong to mortgage token. "General Incorporeal Property" can be mortgage token in U.S.A., and in the article 882 of "The Civil Code of Taiwan" stipulate: Weigh on the ground, the tenant rights, and allusion quotation rights forever must write a mortgage contract and apply for the quality registration to its administrative department. The contract of hypothecate come into force from the day of registering. I think provision on the mortgage token in our country is deficient, Intellectual property rights should exist as mortgage token but as quality token, because Intellectual property rights accord with the regulation of the mortgage token instead of according with quality token, so it should make a self-criticism.

\subsection{The Intellectual property rights has nature different from the ones of quality token but similar to the nature of the mortgage token very much.}

First, the rights of the target weighed as the quality according to the stipulations of our country's Assurance Law, such as first kinds of draft, cheque, cashier's cheque, bond, deposit certificate, warehouse receipt, bill of lading and second kinds of share, stock that can be transferred in accordance with the law being all rights of the security, these rights have a common characteristic : It produces in order to eliminate. Generally speaking, the owner's purpose is eliminated because of using once, and does not lie in its long-term repeated usufruct to obtain benefit. And the mortgage token one is generally real estate, movable property and some rights taking using benefit as purpose, the Intellectual property rights is a rights taking repeated use as purpose, so Intellectual property rights and the targets of hypothec have common characteristics in using for incomes repeatedly.

Second, quality token like creditor's rights, other rights of securities such as draft, promissory note, cheque, etc. are relativity rights in nature and the Intellectual property rights is marked with absolute rights. Similar to it, the mortgage token one such as the ownership to real estate and movable property, usufruct based on real estate and so on are absolute rights. So, Intellectual property rights and hypothec have something in common in relative people of the rights. This shows that the Intellectual property rights has similar characteristics that the mortgage token had.

\subsection{Regarding Intellectual property rights as the target of quality rights is unfavorable to maintain the interests of the pawnor and the realization of the rights of the pawnee.}

With respect to the pawnor, though the pawnor still possess the object, the pawnee control the certificate in the quality rights of Intellectual property rights, so the income punish rights of pawnor will have some restriction. For example, article 80 of Assurance Law of our country stipulates: After the rights offering in article 79 of the law stipulated, the pawnor can't transfer or permit others to use ,but after the agreement of pawnee, he can transfer or permit others to use. The transfer fee, licensing fees pawnor got, people of income should pay the creditor's rights or the third person appointing with pawnee first. This doesn't accord with the principle of making the best use of everything and the principle of the owner enjoying absolute rights of thing in Law of real rights. To pawnee, the purpose of the pawnee is to control the exchange value of the Intellectual property rights, but the exchange value of the Intellectual property rights often has special attribute in fact, such as the Copyrights, Exclusive Rights to Use A Trademark, Trading Company Rights, all of these rights can't realize without the assistance of pawnor, quality people value their ,so the interests of pawnee also receive certain restriction. So Intellectual property rights as quality token have disadvantage to pawnor and pawnee.

\subsection{The Intellectual property rights, as the mortgage token, accords with the development trend of the legal principle of modern Law of real rights.}

Legal principle of Real rights requires kind, content, effect, etc. of real rights must have clear regulation and the real rights is invalid or have no effect as the real rights if it's not according with the legal principle of the real rights . Legislation of our country mainly prescribes real estate, movable properties and some rights based on real estates that can establish hypothec, (the concrete as the above-mentioned). So in our country, the range of the rights to mortgage is limited in a very narrow space and the right is mostly used for establishing quality rights. For example, the following rights in 75th regulation of our country's "Assurance Law "can be hypothecated: (1)Draft, cheque , promissory note , bond, deposit certificate, warehouse receipt, bill of lading; (2)Share, stock that can be transferred in accordance with the law; (3) The exclusive rights to use a trademark that can be transferred in accordance with the law, patent rights ,proprietary of copyrights; (4)Other rights that can be hypothecated in accordance with the law. Article 79 stipulates: Impawn with the exclusive rights to use a trademark that can be transferred in accordance with the law, patent rights and proprietary of copyrights, pawnor and pawnee should conclude contract in writing and apply for the quality registration to its administrative department. The contract comes into force from the day of registering. If the target of the quality of the legal provisions rights meets the current social economic development's needs, it is certainly 
ideal. But the constant changes and lagging of legislations of social economy has determined that the law can not consider the kind and content of the real rights in an all-round way, so there must be shortcomings in the law. In order to avoid the shortcoming that comes from the legal doctrine of the real rights, nowadays the legal principle of real rights in countries with continent law has already been relaxed to some extent. With respect to the theory, there is "legal real rights are ignored", "the law includes common saying", "the real rights admits limitedly in common", "the legal real rights is relaxed",and "the legal real rights is relaxed" is adopted by most scholars among them. "The new kind or different content of real right, whether permit by legal doctrine of the real rights, whether it disobeys the masterdom and absolute protection of real rights and whether it could be announced to ensure trade's security as the criterion for the judgement. If it accords with the criterion and there is benefit and need in the society really, we can regard that it doesn't to disobey with the legal doctrine of real rights, when the operation can be relaxed through the legal doctrine of the real rights, whether real rights on the common law could exist should base on the degree"(Xie Zaiquan,1999:p48).So, outwardly, the Intellectual property rights as the mortgage one is disobeying legal principle of real rights doctrine, but we can find Intellectual property rights as hypothecate token accords with modern trend of real rights after observing carefully and the law should not ignore this development trend but should stipulate the Intellectual property rights existing as the mortgage token. Certainly, under the frame of the current legislation, before the law has revised the target of the hypothec, we should still follow the demand of the legal doctrine of the real rights, because the token of real rights is legal is one of the demands of the legal doctrine of the real rights.

In a word, the quality of the Intellectual property rights as the quality token has a great deal of places deficient, in order to avoid the existence of these drawbacks in legislation, there is inclination shifted to the hypothec in some aspects. Legislators should face the deficiency and make a response in time in order to meet the needs of development of social economy. Certainly, not every Intellectual property rights can be regarded as the mortgage token. To distinguish the kind of the target of hypothec and quality rights, the most basic reason lies in that the hypothec is the rights not taking occupying as important document of announcement. So, the Intellectual property rights must be able to announce by way of registering and then can be regarded as the target of the hypothec.

\section{Mortgage system of domain name rights}

\subsection{The domain name rights can be the mortgage token}

Foregoing paragraphs expound the characteristic as mortgage token, it has illustrated Intellectual property rights should be target of hypothec rather target of quality rights certainly and necessarily and it has analyzed in terms of civil rights that the rights of the domain name should be a kind of independent Intellectual property rights rather the target of quality of rights in our country. Then, whether the domain name rights as the Intellectual property rights can be regarded as the mortgage token .I think the key to answer this question lies in proving whether the rights of the domain name accords with the essential characteristic of the mortgage token. (1)With respect to that mortgage token should not violate state policies and public interests, domain name rights should protect by law, from the aspect of the legitimacy of the target, it doesn't obviously violate above-mentioned demands to establish mortgages on the rights of the domain name. (2)Domain name rights as mortgage token accords with the value rights, changeable rate and the principle of announcement of hypothec totally. (1)The domain name right is a kind of rights worth exchanging. The object of the rights of the domain name is a difficult thing that could be touched, so the rights of the domain name belongs to the category of the invisible proprietary and this is the most obvious characteristic that rights of a domain name is different from the real rights. It is blameless that the right of the domain name is worth exchanging. On one hand, the rights of the domain name is condensing designer's intelligence achievement of work, so it has the value in the meaning of economics; On the other hand, the rights of the domain name is obviously the incorporeal property with use value, so it has two basic attribute of goods like this: Value and use value. According to principle of economics ,the property with attribute of the goods used for exchanging obviously having exchanging value and certainly have appraising at the current rate nature. So domain name rights possess value of rights as mortgage token demanded in this way. Domain name rights can be Intellectual property rights used for goods of trade, in the beginning implemented of the system of domain name registration in our country, in order to prevent people who rush to register domain name from utilizing domain name to coerce relevant interests subject to seek illegal interests, our country limit the transfer of domain name, for example, 24th regulation of "Temporary management means of Chinese internet domain name registration "says, the registered domain name can be altered or cancelled, mustn't transfer or buy and sell. So according to this regulation, the domain name demonetizes things, can't be exchanged. But14th regulation of "CNNIC domain name registration implementing regulations"2002 make registered domain name can be transferred. In this way, domain name has the nature to exchange as mortgage token, variable price in other words. (3)The domain name rights as the mortgage token is according with the demand of hypothec to announce in the form of registering as the important document. Because foregoing paragraphs demonstration in a certain and necessary respect, Intellectual property rights can establish hypothec, and can announce the in the form of registering. In addition, the Intellectual property rights establishes the quality rights is by way of registering to announcement too under the existing legislative frame, the rights of the domain name, as one kind of the Intellectual property rights, certainly can be announced in the way of registering. So from 
certain and necessary respect, domain name rights accords with the demanding of announcement in the way of registering. In a word, the rights of domain name, as a kind of new-typed Intellectual property rights type, accords with an essential characteristic to be the mortgage token.

\subsection{The structured mortgage system of domain name}

The mortgage of Intellectual property rights represented by rights of the domain name is a piece of new things in the real rights legislation, we must make detailed planning in the form legislating and concrete system designing, and then can realize the science and practicability of legislation. I think we should give the special concern to the rights mortgage of domain name in two following respects.

\subsubsection{Way of stipulating of the domain name as mortgage in legislating}

The rights of the domain name can be realized through two kinds of ways in the law of real rights as the target of the hypothec. The first way is enumerating the kind of Intellectual property rights accords to the essential characteristic of the mortgage token in the property that can be mortgaged and the rights of the domain name is certainly included. Through this way we can get the clear and convenient purpose that is suitable to apply of law. Second way is we can give the regulation in assembled mortgage of enterprise property, it is to establish domain name rights in the form of aggregate of an enterprise to mortgage to achieve the goal of establishing the hypothec. The legislative style has been regulated in two real rights law drafts by our country scholar. The 2, 3 items of article 295 in the real rights law draft drafted under the care of professor Liang Huixing regulated: The mortgagor can mortgage the property mentioned above in the lump. Referred property aggregate in item 5 of the first paragraph of this article, refers to the property unit combined property and rights that can transfer and register, such as the specific real estate , usufruct, movable property , Intellectual property rights etc., but it does not include movable property such as airborne vehicle, shipping and locomotive ,etc.(Liang Huixing,2000:p603).442 article of " The proposed real rights draft of China "which is drafted under the care of Professor Wang Liming stipulates: The property mortgaged collectively includes all property that mortgagors has and has the rights to punish when establish mortgages, and also include movable property, real estate, usufruct and Intellectual property rights. But the property forbids to mortgage according to the legal provisions must not be the component of mortgage. (Wang Liming, Guo MingRui, Pang Shaoshen,\& Mei Xiaying.2001:pp111-112). We can know it easily that the two above-mentioned real rights law drafts to the regulations of the Intellectual property rights mortgages both stipulate in the form of collective mortgage. Such legislative way has adhered to the regulation of our country's current legislation, but the author thinks these two kinds way are not perfect enough. Just as what was stated in foregoing paragraphs, as the domain name rights of the Intellectual property rights totally accords with the demand to be target of the hypothec and the thing lacked is the regulation of the legislation now. But the way to legislate is still very important, the regulated way of the law will influence the suitable result of the law. If we make the domain name rights mortgage in the form of collective mortgage can cause financing discommodiousness, because it doesn't establish the hypothec with the property of the financial group of the whole enterprise in any case. On the contrary, if we stipulate the domain name can settle hypothec singly, that is to adopt the first kind of legislative ways, will meet the needs of financing of factor's different scale.

\subsubsection{The design of relevant system of domain name rights to mortgage}

Considering the nature of the domain name rights as a kind of new-type and special invisible proprietary rights, it must perfect in relevant system and guarantee the legislation to have extensive suitability. First of all, we should stipulate the announcement system of the rights of domain name rights to mortgage in relevant legislation .According to the stipulations of our country's current law, chattel mortgage generally adopts the way to occupy and hand to give announcement, special chattel mortgage take announcement in the way of registering and real estate mortgage take the announcement way to register. The mortgage of domain name rights has the characteristics that different from chattel mortgage and real estate mortgage, just as what foregoing paragraphs have said domain name rights is independent Intellectual property rights, in current legislation, the Intellectual property rights stipulates by way of hypothecating and its announcement way is to register. I think, the way of registered announcement has considered the special attribute of the Intellectual property rights and it should insist in the mortgage of domain name rights, otherwise it possibly will jeopardize the third person's interests in the trade of the market. So we should perfect the resignation system of the mortgage of domain name rights in relevant legislation, specifically we should stipulate the registering organ , procedure registering of the mortgage of domain name rights, etc.. Secondly, we should perfect the value assessment mechanism of the mortgage of domain name rights. Resources of the domain name have characteristic of limited and uniqueness, the domain name as incorporeal property have unique use value and investment value. There is a lot of successful domain name trade in the world. Business. Com occupies the highest price with the knock-down price of 7,500,000 dollars. In numerous domestic famous websites, there are a lot of experiences of buying the domain name too. For instance, Beijing Youth Daily buys yent.com domain name, Shenzhen Tengxun Company buys QQ. Com domain name, Sinochem net buys ZJ. Com domain name, www.qianlong.com buys Qianlong. Com domain name,etc.. The knock-down price of above-mentioned domain names is several tens of thousands of RMB at least and a lot is up to a 
million dollars, we can find out the enormous commercial value of the outstanding domain name from it. But what merits attention is the value assessment mechanism about domain name rights mortgage is deficient and there's not a authoritative organ of assessment mechanism of domain name at present. So, it is very necessary to set up or appoints an authoritative organization to evaluate value of the domain name in our country, and we should also make the objective value evaluation criterion of domain name as soon as possible.

\section{References}

Hao Dong. (2004). The right of the domain name and the research of relevant rightss. http://www. blogchina. com/new/display/25380. html(March 11,2004).

MingRui Guo. (1999). Assurance Law. Beijing: China University of Political Science \& Law Press.

Huixing Liang. (2000). Drafted proposes of China's real rights law. Beijing: Publishing house of social scientific literature.

WeiQiu Long. (2003). Civil law introduction. Beijing: China Legal System Publishing House.

Bu Shou. (2003). Information network and the law front of the new and high technology. Beijing: The publishing house of the law.

Liming Wang, MingRui Guo, Shaoshen Pang \& Xiaying Mei. (2001). Propose draft and instruction of real rights of China.Beijing:China Legal System Publishing House.

ZeJian Wang. (2001). General provisions of civil law. Beijing: China University of Political Science \& Law Press.

HanDong Wu. (2000). Law science of the Intellectual property rights. Beijing: BJ University Press.

Zaiquan Xi. (1999). Real rights theory of the civil law. Beijing: China University of Political Science \& Law Press.

YuMin Zhang. (2001). The concept of the Intellectual property rights and legal characteristic. Modern law science. (5). 105.

\section{Notes}

Note 1 . T his text only refers to the right of the commercial domain name besides especially proving.

Note 2. Umbro International Inc is judged by district court and got the request right of about 20,000 dollars to a 3263851Canada Inc company correctly. In order to make this right to carry out, Umbro Company propose the domain name management company NSI to mortgage 38 domain name that Company have to auction in order to obtain the damages in the court. As to this, NSI Company litigate to the higher court of the state of Barginia, and maintain that domain name is one service item that produce by contract between person who utilize. If making it stop serving is tantamount to losing this function, so, the domain name can't be auctioned as the target of mortgage. The high court of Barginia think"domain name is a valuable and invisible new shape of intellectual property right, and do not deny it as the target of the mortgage ". The judgement makes NSI Company to stop above-mentioned domain names and forces to carry out the mortgage. NSI Company refuses to obey, appeal to the Supreme Judicial Court of Barginia then. The judgement of the Supreme Judicial Court is that: Because of the following reason, the domain name can't become the target of the mortgage and cancel the original sentence. The domain name is the right based on service contract between NSI Company and persons who utilize, there are dense integral relation between the services of appellant and the right based on this contract, if service can't store, the right is unable to cash. In addition, the right on this kind of contract should not become the target of the mortgage as a kind of "debt". Certainly, not any right on contract can become the target of the mortgage, contract that can obtain certain money and interests can regard as target of mortgage. 